\title{
The analysis on labor-intensive industry in Xinjiang
}

\author{
Yukun Zhao \\ Xinjiang university of finance \& economics , School of economics,Xinjiang, Urumqi 830012 \\ huner2011@foxmail.com
}

Keywords: Industrial Transfer, The Labour Supply, The Labour Demand

\begin{abstract}
Since China's reform and opening up, relying on the driving power of labor-intensive industries, the economic level of the eastern region has achieved a qualitative leap. However, with the rising labour shortages and wage costs, labour-intensive industries in the eastern region have lost the comparative advantage to start looking for a new "habitat". This paper sets out to find the most main factors of "habitat" from the effects of labour-intensive industries, the perspective of the labour supply and demand. It respectively forecasts the labour supply and demand in the coming decade based on GM $(1,1)$ grey prediction model and Cobb Douglas production function model of Xinjiang with the aim of making the autonomous region government know the situation of the future labor supply and demand in Xinjiang to be able to take corresponding policy ahead of time by the predicted results. The predicted results show that at present the labour force has been in short supply in Xinjiang and the supply gap has appeard in the labor force. Moreover, the gap has a tendency to enlarge gradually. If Xinjiang wants to undertake the processing and manufacturing industries in the eastern region, the corresponding policies and measures need to be taken.
\end{abstract}

\section{Introduction}

The labour-intensive industries refer to the industries which the production relies mainly on the heavy use of labor with low degree of dependence on technology and equipment. Compared with the production costs and expenses on equipment depreciation and research and development in the production costs, the one who accounted for a larger proportion is the standard of measuring them. The labour-intensive industries involve the primary industry, the secondary industry, the tertiary industry and various ownerships and cover both urban and rural areas. They emerge and develope throughout the whole process of economic development. The labour-intensive industries have moved gradually from the stage of dominant position to the stage of non-dominant position. It is the impassable stage in the development process of each country and the area in history. Will the situation of labor supply and demand in Xinjiang in the next decade affect its undertaking these labor-intensive industries?The paper will get the conclusion from the predicted results about the labor supply and demand in $2014-2025$ in Xinjiang.

\section{The Prediction of the Supply and Demand of the Labor Force}

The Prediction of the Supply of the Labor Force. The Prediction Thought. This paper will predict the supply situation of the labor force in Xinjiang in the next decade by two methods. One is calculated by deducting the jobless population (people who do housework at home and people without working capability) and students at school from population of working age. Considering the availability of the data and the small number of people who do housework at home and people without working capability, so the labor supply approximately equals the numbers by deducting students at school from people of working age. The other one is 1 by getting the prediction value firstly with the population of working age and the labor participation rate by GM $(1,1)$ grey prediction model, then multiplying the predicted values of the two. Finally the two methods have been gives equal weight to get the final result.

Model Building. The core idea of GM $(1,1)$ grey prediction model proposed by Professor Deng Julong is to make certain transformation for the irregular data sequence to get new sequences with 
certain rules and approximate with curves further. This model has the advantages to need less data and have less prediction errors and be reliable, so it is often applied to the prediction of population. Prediction steps:

(1) Set the original sequence is $X^{(0)}=\left\{X^{(0)}(1), X^{(0)}(2), X^{(0)}(3) \ldots \ldots . X^{(0)}(n)\right\}$

Do an accumulation by the following method to get a generated sequence ( $\mathrm{n}$ is the sample space)

$$
X^{(1)}(i)=\sum_{m=1}^{i} X^{(0)}(m) \quad i=1,2 、 3 \ldots \ldots n
$$

(2) Use the least square method to get the parameters "a, u". Set

$$
\begin{aligned}
& B=\left[\begin{array}{cc}
-\frac{1}{2}\left[x^{(1)}(1)+x^{(1)}(2)\right] & 1 \\
-\frac{1}{2}\left[x^{(1)}(2)+x^{(1)}(3)\right] & 1 \\
\vdots & \vdots \\
-\frac{1}{2}\left[x^{(1)}(n-1)+x^{(1)}(n)\right] & 1
\end{array}\right] \\
& y_{n}=\left[x^{(0)}(2), x^{(0)}(3), \cdots, x^{(0)}(n)\right]^{T}
\end{aligned}
$$

The parameter identification $a, u \hat{a}=\left[\begin{array}{l}a \\ u\end{array}\right]=\left(B^{T} B\right)^{-1} B^{T} y_{n}$

(3) Figure out the model of GM $(1,1)$ :

$$
\hat{x}^{(1)}(i+1)=\left(x^{(0)}(1)-\frac{u}{a}\right) e^{-a i}+\frac{u}{a}
$$

The reduction value is

$$
\left\{\begin{array}{c}
\hat{x}^{(0)}(1)=\hat{x}^{(1)}(1) \\
\hat{x}^{(0)}(i)=\hat{x}^{(1)}(i)-\hat{x}^{(1)}(i-1), i=2,3, \cdots, n
\end{array}\right.
$$

The Prediction for the Demand of Labor. Prediction Principle. In this paper, the production function method is adopted to predict. Due to the demand of labor, the number of employees, is mainly affected by the economic growth, the cobb - Douglas production function can be used for prediction. This function is made by American mathematician cobb and economist Paul Douglas. They created the production function when they investigated the relationship between the input and output together. It is the most widely used production function in economics. According to the cobb - Douglas production function

$$
Y=A K^{\alpha} L^{\beta}
$$

we can see that the demand of labor is determined by the technical level of A, the capital input $\mathrm{K}$ and gross domestic product Y. For the sake of study it conveniently, this paper assumes that the technical level and capital investment in the prediction period remain unchanged. In this way the change of GDP will become the main factors affecting employment.

When we calculate the amount of employment, we need to assume the percentage of annual growth about GDP in 2014-2025 in Xinjiang. By analyzing the annual growth rate of GDP in 1978-2013 in Xinjiang and considering comprehensively the macro economic policies of the country and the development objectives in xinjiang, we can judge basically that the growth rate remains high first and then low after that. For this reason, the paper made the following assumption . We treat the high growth rate as annual growth rate of 11\% in 2014-2020 and annual growth rate of $10 \%$ in 2021-2025. Because there are 14 in total for annual economic growth which remained in more than $11 \%$ in 35 years. It is completely possible to keep this growth rate. We treat the middle 
growth rate as annual growth rate of $10 \%$ in 2014- 2020. Because the average annual growth rate in 35 years is $10.46 \%$. We treat the low growth rate as annual growth rate of $8 \%$ in 2014- 2020 and annual growth rate of $7 \%$ in 2021- 2025. Because there are more than 10 in total for annual economic growth which remained in the range of $8 \%-10 \%$ in 35 years. While there are only two years of 1996 and 1989 with the growth rate below 7\%.

The Building and Estimation of the Model. Take the logarithm from both sides of equation(1), and establish the equation.

$$
\ln L_{t}=\alpha+\beta \ln Y_{t}+\varepsilon_{t}
$$

According to the relevant data of statistical yearbook in xinjiang in 1995-2013, we make GDP to adopt the constant price in 1978 and calculate the data. Then by using least square method to estimate, we can get that there is a positive autocorrelation with the estimated results. By using the generalized difference method to eliminate the positive autocorrelation, after that we obtain the final result.

$$
\ln L_{t}=0.2462 \ln Y_{t}+5.12
$$

The test $t$ and the test $F$ of the result are all significant.The goodness of fit $R=0.91$. with high fitting shows that the model is good. The results which are got by predicting the number of employment in 2014-2015.

The Prediction Results and Analysis. We take the assumed high, middle and low growth rate, the three different growth rates of GDP into the formula (3) to get the predicted value of the number of employment. Then according to the situation of growth rate which Xinjiang is most likely to maintain in the future, we respectively give the weight of 0.3 to the high growth rate and the low growth rate and the weight of 0.4 to the middle growth rate. At last we calculate the demand of the labour force in 2014-2025. Compared with the predicted value of the supply of the labour force in 2014-2025, we can get that the shortage of the labour force has appeared in Xinjiang, which inosculates with the predicted results of the whole country and other respective regions. And the enlargement of the gap of the labour force gradually appears. In 2014 the demand of the labour force is 2 million more people than the supply of the labour force. And in 2015 the number is 4 million. What's more, the number has increased year by year. This is obviously very bad for Xinjiang to undertake the intensive industries in eastern region.

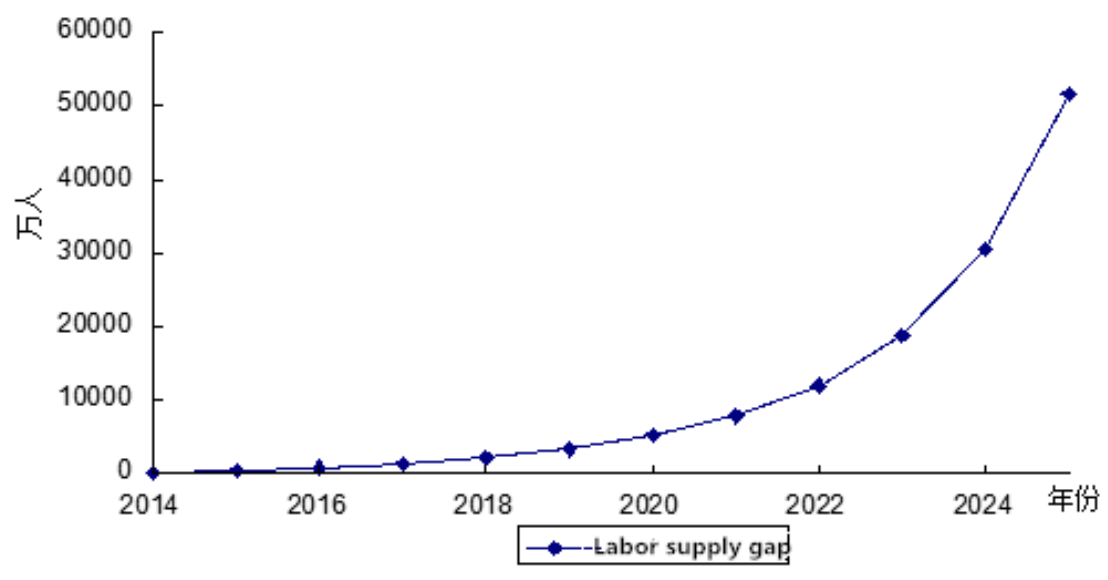

Fig. 1 Labor supply gap

\section{Summary and Conclusion}

It is true that Xinjiang has its special situation. The data of working age population used in this paper is only 1\% sampling survey data. A large number of herdsmen and rural surplus labor force may not have statistics to the working age population. But the trend of the shortage of the labour 
force can be certainly, the gap has been gradually enlarging. The supply and demand of the labour force is the decisive factor which decides whether the labor intensive industries transfer in and can remain and keep them after the transfer. If the government of Xinjiang didn't realize this, didn't attract the labor intensive industries to come in by preferential policies, didn't take the relevant policies to increase the supply of the labour force, these manufacturers would find that the supply of the labour force couldn't meet the requirements for them to start to produce products or take very high labor costs, and at last they would have to find new "habitat". This is not inconsistent with the original intention which the industries of the autonomous region are introduced to obtain the economic benefits. Therefore, the government of the autonomous region should adopt corresponding policies. We give some suggestions from the following several aspects: 1) Fully mobilize the enthusiasm of the surplus labour force in rurual areas. 2) Improve the system of vocational training to prevent the structural unemployment. 3) Correctly guide young people to do the career planning well.

\section{Bibliography}

[1] L.J. Gao. Under the New Situation the Prediction Analysis of the Supply and Demand of the Labour Force and the Adjustment of Employment Policy in Jiangxi. Nanchang University, 2010.

[2] S.J. Zhu. The Analysis and Prediction of the Supply and Demand of the Labour Force in Guizhou Province.The Guizhou University of Finance and Economics,2011.

[3] L. Cheng. Research on the Trend of the Supply and Demand of the Labour Force in China in 2010-2050. Nanjing University, 2012.

[4] X.C. Zhao, Y.Y. Zhou, Z. Wang, X.Z. Hong. The Resarch on the Prediction of the Population Scale in Hunan Province Based on GM $(1,1)$ Grey Model. Journal of Yulin Normal University,2010,02:11-15.

[5] M.Z. Qi. The Prediction of the Supply and Demand of the Labour Force in China in 2010-2050. The Research on Population, 2010,05:76-87.

[6] C. Zhang. The Prediction of the Supply and Demand of the Labour Force in China in 2020 and the Trend of Unemployment. The Economic Research of Nankai, 1997,06:20-25.

[7] S.Y. Zhang. The Analysis of the Working Age Population in China Based on the Census Data. The Analysis of Market and Population, 2003,06:33-38+66.

[8] X.P. Wu. The Resarch on the Trend of China's Employment of the Labour Force in the Future. The Population in the South,2000,01:50-55.

[9] Q.S. Guo. The Research on the Supply and Demand of the Labour Force in the City of China and the Problems of Employment-- a Case Study of Shanghai City. Society and Science, 2004,11:63-71.

[10] Han Ying, Ma Ping, Feng Yan. The Resarch on the Prediction of the Supply and Demand of the Labour Force in Liaoning Province.Journal of northeastern university( Society and Science Edition), 2009,03:226-229.

[11] P. Pan. The Resarch on the Prediction of the Supply and Demand of the Labour Force in Sichuan Province. The Southwest University of Finance and Economics,2011.

[12] M.Z. Qi. The Predition of China's Demand of the Labour Force with Medium and Long Term in the Future. The Population in the Northwest, 2011,04:1-5. 